\title{
Study and Application of Urban Flood Risk Map Information Management System Based on SOA
}

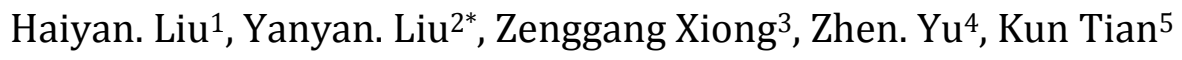 \\ ${ }^{1}$ Department of Computer Engineering, Beijing Information Technology College, Beijing, China. \\ 2 Department of Basic Courses, Institute of Disaster Prevention, Beijing, China. \\ ${ }^{3}$ School of Computer and Information Science, Hubei Engineering University, Xiaogan, China. \\ ${ }^{4}$ School of Information, Beijing Wuzi University, Beijing, China, Beijing, China. \\ ${ }^{5}$ Office of the South-to-North Water Diversion Project Construction Commission of Beijing, Beijing \\ China.
}

* Corresponding author. Tel.: 01085305254; email: liuhaiyan@bitc.edu.cn

Manuscript submitted January 10, 2014; accepted March 28, 2014.

\begin{abstract}
In order to improve the urban flood defenses management and to provide scientific decision-making for the urban flood defenses, the paper develops the urban flood risk map information system based on the Service Oriented Architecture (SOA). The system builds the system architecture based on SOA, and uses the module method to design the application systems, and builds the application support platform based on SOA and the Enterprise Service Bus (ESB) to solve interconnection among the application systems. Our application result indicates that the system can not only improve the urban flood defenses management but also realize the visual effect of multi-user distributed access and three-dimensional dynamic simulation. The system provides the effective reference on the flood hazard mapping, the flood control planning and the emergency preparedness.
\end{abstract}

Key words: Urban flood, risk map, information management system, service oriented architecture (SOA).

\section{Introduction}

In recent years, with the rapid development of urbanization in China, disaster-forming environment, hazards, receptors and prevention capacities in urban flood disaster system have changed. Some new features of flood disaster appear in urbanized areas, which bring a series of challenges to urban flood control and disaster mitigation [1]. The urban flood risk map has important significance to strengthen flood control command and emergency management, to improve non-engineering measures of flood control and disaster and to protect social stability and sustained and stable development of the national economy [2-3]. With the development of information technologies, geographic information technology, remote sensing technology and network technology are widely applied in the making of flood risk maps. The corresponding flood risk map information systems are formed. Construction of urban flood risk map information management system has improved the efficiency of rivers information management and the quality of engineering management. It is an important role to prevention of flood and scientific decision-making of avoiding disaster [4].

In 2002, Shanghai city developed the Shanghai flood risk map which had become early the project example of flood risk map information management system based on GIS. The flood risk map analyzed the flood risk caused by rainfall and established the GIS-based information query system [5]. In 2004, Wenzhou City developed the flood risk map based on three-dimensional platform in order to solve the problems that the two-dimensional flood risk map had poor flexibility and poor intuitive performance in flood control applications[6]. Liaoning 
Province developed the Liaohe River flood risk map and established a WebGIS-based information management system [7], [8]. The paper gave the design method of database of flood risk map information management system and integration method of heterogeneous data arming for integration problem of similar heterogeneous data provided by multiple Web services. It combined the basic tables and field dictionary tables to store relative information of flood risk map in order to improve data sharing capability. These were benefit to standardization and generalization of flood risk map information management system according to the specific application field of flood risk map compilation. In (2011, taking Baoding as example, the paper summarized the technical experience of risk map compilation and compared the urban flood risk maps with flood risk maps of rivers and lakes, detention basin flood risk maps, the flood risk maps of reservoir flood and got the features of urban flood risk map [9].

Although the development of urban flood risk map information management system has achieved some success, these systems have some problems in terms of flexibility, usability, scalability and information exchange with the existing water resources business systems. The study of three-dimensional flood risk map information management system which can visually display the relationship between flood and ground object is few based on networking and three-dimension. Therefore, this article develops a three-dimensional flood risk map information management system by using service-oriented architecture (SOA) architecture, modular design method and Web Services technology. The system can not only effectively improve data sharing ability but also has a lot of fine characteristics such as good scalability, crossing platform and easy integration. Topography and geomorphology and buildings are simulated, inundation process and inundation loss are simulated, dynamically analyzed and calculated by using the historical flood data, topography and geomorphology data and socio-economic indicator data, water conservancy project data and waterproofing building data. The system can forecast the flood according to historical hydrographic data and flood rainstorm data, make flood warning preparedness and emergency response preparedness, provide chart plotting function of visualize personnel evacuation and material transfer lines on maps.

\section{System Design}

\subsection{System Design Principle}

Urban flood risk map information management system is an information platform in sharing, management, application. The following principles needs be obeyed in process of system design [10].

\subsubsection{The principle of general planning, gradual implementation and gradual improvement}

\subsubsection{Practicality of system design}

The practicality is the basic principles of application software design. The paper takes use of three-dimensional platform to achieve practicality. The display way of three-dimensional platform ensures the friendly interface of user and strong operability. It is convenient to browsing, inquiry and guidance the flood risk map and is benefit to analysis and access of risk maps.

\subsubsection{Flexibility of architecture}

The compilation of flood risk maps is underway, the associated systems are not perfect, application field and application methods are constantly dug and updated in our country. Therefore, the system should meet their requirement of extension and updating. As the condition platform, the system should have good scalability and cross-platform and is easy to integrate with flood prevention decision \& command system and other information systems in order to adapt to large-scale, complex application requirements. The paper takes use of object-oriented method to achieve the flexibility and scalability of the entire system.

\subsubsection{Consistency of standard specification}

The system needs to integrate multi-source, heterogeneous, distributed spatial geography data and resources, however, most of the data and resource required originates from sharing. The quality of sharing data is directly 
related to the functions of system and service quality. In order to rapid deployment of compiling work of flood risk maps and spreading use of results, it is necessary to make use of standard specification for the compilation results.

\subsubsection{Data security}

The basic data of flood risk maps is mostly secure data, therefore, urban flood risk map information management system should have effective security protection system in order to ensures the availability, integrity and confidentiality of data information.

\subsection{System Architecture}

The Architecture of the system is presented in Fig. 1.

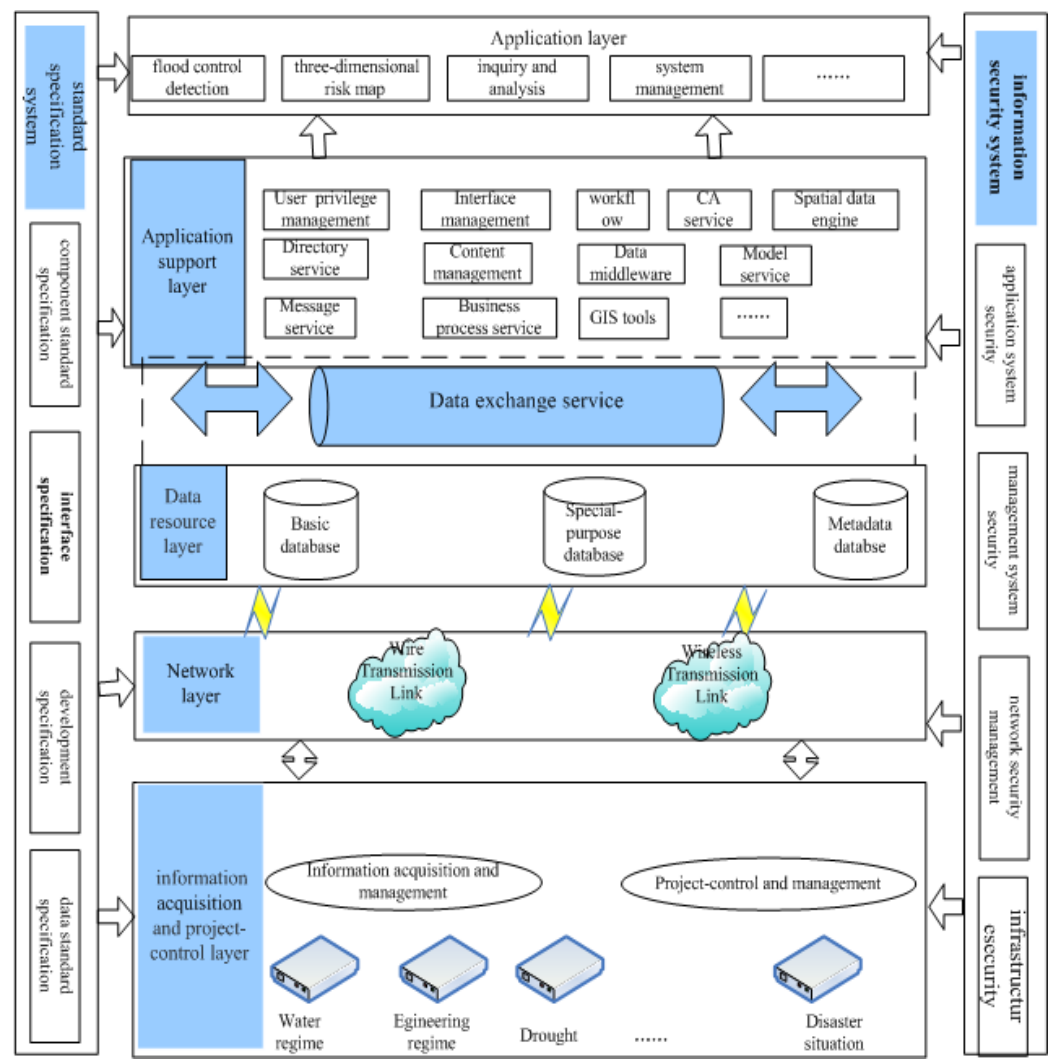

Fig. 1. The architecture of the system.

The urban flood risk map information management system mainly consists of information acquisition and project-control layer, network layer, data resource layer, application support platform, data exchange layer, standard specification system, information security system and application layer.

\subsubsection{Information acquisition and project-control layer}

The information acquisition and project-control layer which provides data support service for the system is the foundation of urban flood risk map information management system. This layer lies the acquisition station of information system and actuating station of project management decision-making. Its technologies are relatively complex, operation, maintenance and application are different from other layers. The layer is one of the main sources of information of this system and forms the shared resources. In this layer, the data information achieves conversion, validation and data loader by standard components. Transform protocol is more open and can support several upgrades and expansion.

\subsubsection{Network layer}

The network layer is responsibility to transfer the monitoring data and information what the information 
acquisition and project-control layer collected to the application layer and transfer the command of application layer to the next layer. The layer mainly includes the wire transmission link which includes fiber, Coaxial Cable, net wire for the short distance monitoring and control equipments and wireless transmission link mainly includes microwave, radio, GPS, RS for the remote distance equipments.

\subsubsection{Data resource layer}

The data information is classified according to businesses in data resource layer. The name of database and structure specification are to refer to standards of state and water conservancy industry. The data is divided into basic database, special-purpose database and metadata database. The special-purpose database mainly includes system library (storage system modules, permissions, users, roles, and other related information), water and rainfall library (storage introduction, real-time rainfall in watershed, city rainfall, urban rainfall, district rainfall, hydrologic station overview, river flood forecasting, flood forecasting), model library, data bank (including a variety of data), engineering library (reservoir power station information) and GIS database (map data stored in the file).

\subsubsection{Application support layer}

Application support platform mainly supports the construction of the upper application systems, accesses various data, system service, log management, user personalization setting and other operations. Most of the existing business application systems are closed and lack openness, flexibility and integration in process of building water resources informatization [11]-[14]. Although data can achieve the exchange between some systems, and much conversion work need to be done if a wide range of data sharing was achieved. Since each application system used different platform technology, a unified architecture and interface standards are lacking between systems. These information systems can not meet the intercommunication, interoperability, business collaboration and data sharing between applications, therefore resources sharing is hard to realize.

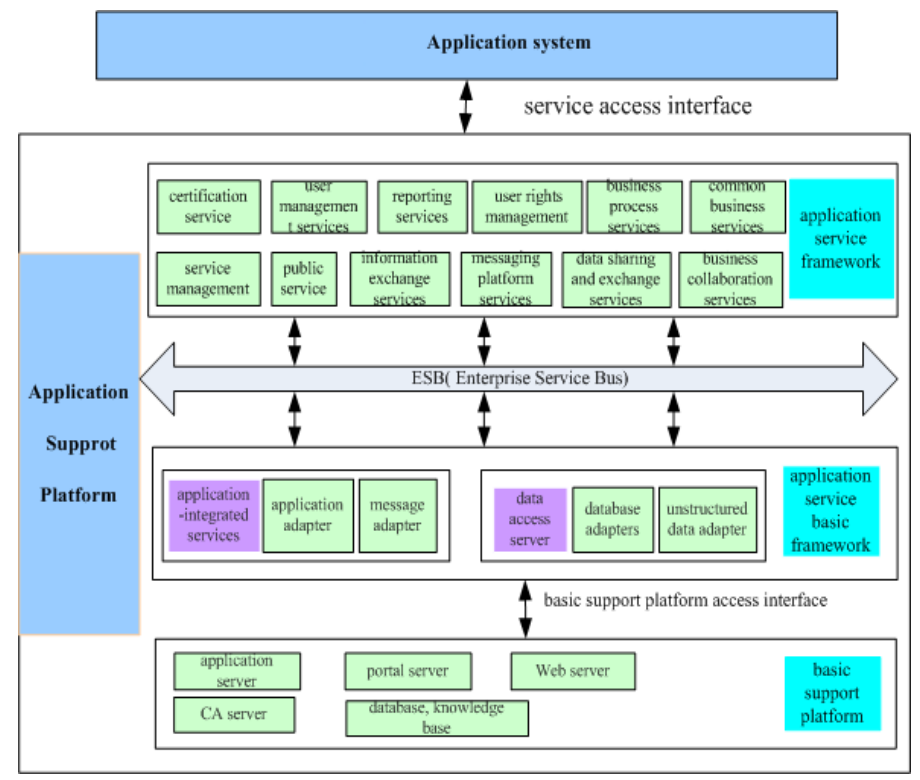

Fig. 2. United application support platform based on SOA and ESB.

In order to solve such problems, application support platform based on SOA and ESB (Enterprise Service Bus) [15] is built to integrate or inherit the existing systems, to achieve integration of different business processes, to facilitate the expansion of the new business system functions and to provide public services for business application construction, information resources integration, information exchange and business collaboration. The platform uses the loosely coupled and scalable design idea to ensure the highly scalability of system. The united application support platform based on SOA and ESB is presented in Fig. 2.

The united application supporting platform includes basic support platform, application service basic 
architecture, application service framework, basic support platform access interface and service access interface. The basic support platform includes application server, CA server, portal server, Web server, database, knowledge base. The application service basic architecture includes application-integrated services (application adapters, and message adapter), data access server (database adapters and unstructured data adapter). The application service framework includes common business services, user management services, reporting services, user rights management, business process services, service management, public service, certification service, information exchange services, messaging platform services, data sharing and exchange services, business collaboration services. The platform takes use of the form of service to implement the various functional components of application service basic architecture layer and application service framework layer to achieve the standard service of intercommunication and interoperability on ESB. Arrangement and combination of services increase the flexibility, reuse and integration of services which provides a convenient and flexible way for accessing of application and business processes restructuring. The service access interface needs to obey the following requirements [16]: (1) Using the standard format of XML document to describe the relationship of combination and timing between business components and functions. (2) Parsed and executed by service executive function.

\subsubsection{Application layer}

Application layer mainly recomposes, integrates and displays various components provided by application support platform according to the business process and provides a good human-computer interaction function to enhance usability and operation of system software.

\subsubsection{Standard specification system and information security system}

The construction principle, policies and regulations, construction management method, technical support and standard system of "unified leadership, unified planning, unified organization, unified management" are to realize guarantee and support of the system. The standard specification mainly includes interface specification, development specification, data standard specification, component standard specification. The information security system mainly includes application system security, management system security, network security management, infrastructure security. The composition of information security system is presented in Fig. 3 .

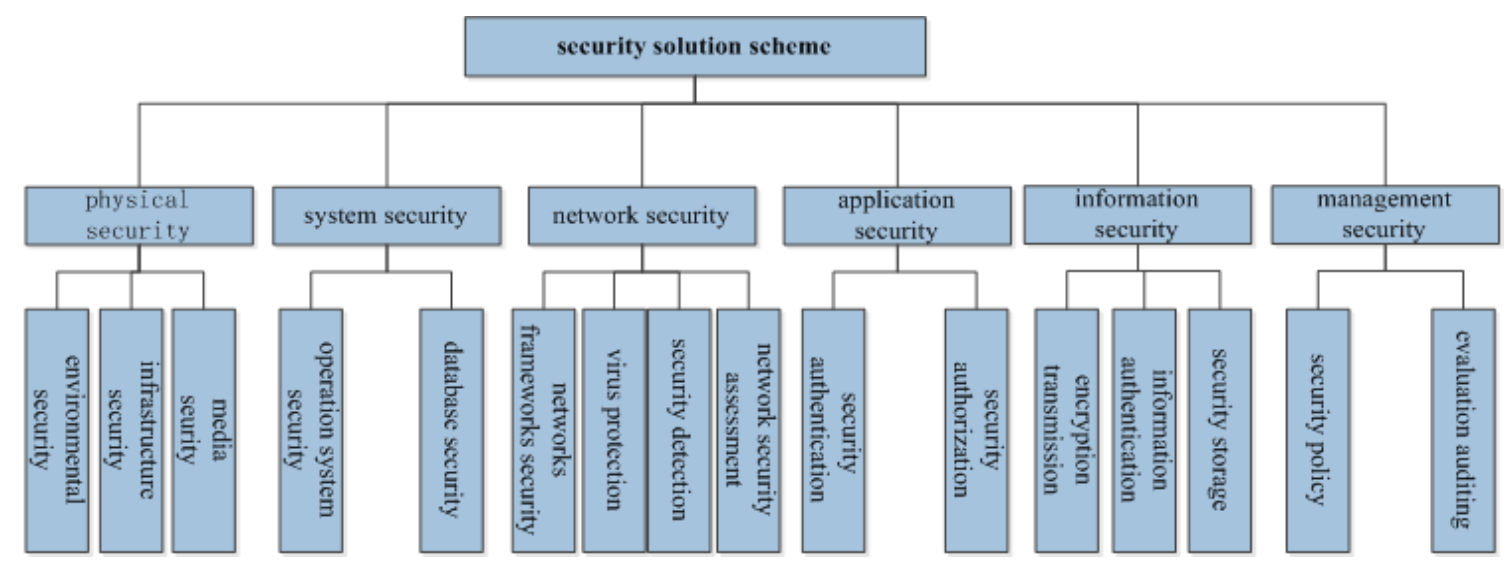

Fig. 2. The composition of information security system.

\section{Key Technologies of System Implementation}

\subsection{Service-Oriented Architecture}

The service-Oriented Architecture (SOA) is a new generation of architecture ideology. It is a platform-independent, loosely-coupled and distributed application architecture which different services communicate each other by interfaces of simple and precise definition and do not involve the underlying programming interface and communication models. SOA can be seen as natural extension after B/S model, 
$\mathrm{XML} / \mathrm{Web}$ and service technology. Service layer is the foundation of SOA and the application layer can directly call it [17]-[19].

SOA can help software engineers to understand the development and deployment way of various components in business-level architecture. It can help the Architects of enterprise system to built the architecture of the entire business system in a more rapid, more reliable, more reusable way. The system based on SOA can more calmly face abrupt change of business. Therefore, the paper chooses SOA to built the architecture of system.

\subsection{Modular Design}

The modular design can not only guarantee that the construction content of each stage has a close association and inheritance in the technical architecture and feature set, can but also guarantee that the construction contents of the various stages is relative independence. It is easy to implement step by step. In the paper, the paper splits and refines the business functions and then merges the functional requirements. The business functions are divided into independent, Flexible and extensible modules. After the completion of the system, the developed modules are maintained and managed.

\subsection{Drawing of Atypical Year Food Risk Map}

Real-time buffer function of Arcgis10 is applied to overcome the problem that the flood risk map makes enormous error in the general water conservancy system. Thus, flood risk map of the middle year between typical year can be calculated in time.

\subsection{Display of Three-Dimensional Flood Risk Map}

In the past, flood submerged area of the two-dimensional flood risk map is drew artificially on the administrative map and is showed in the form of two-dimensional image plus text logo. The shortcomings of the two-dimensional flood risk map are listed as follows:

1) Inundation level and frequency level have been designated when the flood risk map finished compiling. They can not be changed in real time and only can be counted in rough. The submerged area drawn is also discrete and any more accurate submerged area in the middle range can not be gotten. Relative loss data only uses simple interpolation to approximate so that the flexibility is poor. Updating of flood risk maps is also relatively slow due to the demand that the actual disaster data supplies and updates.

2) Because flood submerged area is drew on administrative maps according to historical data only, it can not quite match with actual topography. There are the problems of arbitrariness and error. Especially, in recent years, all kinds of water conservancy projects, road traffic, charts reclamation and other infrastructure construction have changed the landform dramatically so that there is the difference between the submersed areas got by historical data and the actual submersed areas. All these make that the two-dimensional flood risk map can not be well matched with the actual field landform and topography.

3) Intuition of two-dimensional plane submersed areas is poor that visual effect of flooded terrain can not be displayed.

To solve these problems, the paper develops a three-dimensional urban flood risk map information system. The three-dimensional terrain flooded of hydrological calculation cell are calculated according to water level. The system analyzes the disaster in real-time by using the database of historical flood and socioeconomic database while the flood submerging region are demonstrated, provides the displaying of report and graph-text which can be intuitively demonstrated by using the three-dimensional platform. These make up the deficiencies of the existing two-dimensional flood risk map in flexibility, accuracy, intuitive performance.

\subsection{Calculation of Flood Forecasting}

In this system, the collection and transmission processing of rain and water regime, calculation analysis of flood forecasting mathematical model, distribution service for forecast information are as a whole. The system 
takes use of hydrology, hydraulics, river dynamics and other methods to build experienced method of flood forecasting and mathematical prediction model by analyzing and researching flood characteristics and riverbed deformation. In application, real-time rainfall regime, water regime and other real-time information are taken as input to start the model, forecast the flood peak level (flow), flood hydrograph, flood volume, flood control and other flood elements and provide decision basis for flood prevention departments.

\subsection{Real-Time Plotting Technology}

The traditional plotting components have undergone three phases: plotting toolbar based on $\mathrm{C} / \mathrm{S}$, script plotting based on B/S, flex plotting technology based on B/S. The comparison and analysis of technologies are following:

Table 1. Comparison of Three Different Plotting Components

\begin{tabular}{lll}
\hline \hline $\begin{array}{l}\text { Consultation } \\
\text { Decision toolbar }\end{array}$ & Plotting module & Improved plotting module \\
\hline client plug-in & zero client & zero client \\
$\begin{array}{l}\text { simple plotting } \\
\text { function }\end{array}$ & rich plotting function & $\begin{array}{l}\text { based on new Flex technology(Flash } \\
\text { effect) }\end{array}$ \\
$\begin{array}{l}\text { incomplete plotting } \\
\text { content }\end{array}$ & complete plotting content & $\begin{array}{l}\text { join with ArcGISServer9.3 tight, } \\
\text { simple operation }\end{array}$ \\
relatively & complex operation & better stability \\
& poor stability & rich manual mutual Characteristics \\
& joining with GIS platform & better stability \\
\hline \hline
\end{tabular}

In order to improve the matching degree of the map operation, this paper takes use of plotting component based on $\mathrm{B} / \mathrm{S}$ and flex technology to improve response effectiveness and operational characteristics of the map. In this system, characteristic functions of real-time plotting component include:

1) Taking use of $B / S$ version plotting based on Web page to achieve the plotting of point, lines (curves, polylines) and surface(rectangle, circle, ellipse, irregular polygons) of conventional emergency rescue and text.

2) Achieving a more accurate registration among the real-time plotting, plotting content and map based on GIS platform.

3) Expanding the plotting elements and illustration of the flood control businesses.

\section{Implementation and Application of System}

\subsection{System Function}

The flood risk map information management system adopts a modular design idea and sets up flood control detection module, three-dimensional risk map module, inquiry and analysis module, system management module and other business function modules. The flood control detection module mainly includes the water regime monitoring, rainfall regime monitoring, risk map, reservoir power station, information points, columnar section and map tools. The staff in flood prevention office may use functions of the module to finish monitoring the water and rainfall and forecasting flood submerged area, personnel evacuation, disaster evaluation and so on. The functions of map tools mainly include map information, maps ranging, path analysis, elements retrieval, screenshot. The analysis and inquiry module queries various types of data in the form whose functions include water regime inquiry, channel water regime inquiry, reservoirs water regime inquiry, rainfall regime inquiry, reservoir power stations inquiry. The system management modules mainly 
manage the users, user permissions and internal departments of flood prevention office.

\subsection{System Implementation}

The development environment of this system uses MS SQLServer2008R2 as the database server, City Maker as the three-dimensional service platform, ArcGIS Server10.0 as the GIS server, Apache Tomcat as the Web server. In implementation techniques, the system uses java language to develop and chooses the J2EE [20] as development platform. The Web Services module uses open source Apache Axis2 engine. The REST service uses Glassfish Jersey to built. The document retrieval function uses Apache Lucene and the presentation layer uses Flex technology.

\subsection{Application Example}

Luzhou lies at the transition area between southern Sichuan Basin and Yunnan - Guizhou Plateau which has the geomorphic types of the central hill of basin and in mountainous areas around basin. The terrain is south of the high - lying, low - north. The Geomorphological Characteristics of LuZhou city is Yangtze River, Tuojiang river one, secondary terraces, relative elevation of about 20 to 30 meters.

Flood control problem is extremely sensitive and serious in Luzhou city. In order to scientifically and effectively study the city's flood control problems, the system is applied in Luzhou city to provide decision basis for the city's flood control and disaster, accurate prediction of flood peak for flood period and a scientific basisfor ensuring the safe evacuation of people along the river. In application process, the system analyzes the flood risk of atypical year in Luzhou city to determine the flood submerged area, flood arrive time, flood fastest velocity, whole time of flood submerge and flood depth. All flood risk elements submits the results in the form of flood risk map. The system Integrates data sources of water and rainfall in Sichuan flood prevention command office and real-time monitors the water regime and waterfall, provides retrieval and access and statistical analysis of historical monitoring data and provides data support for flood risk map information management system of Luzhou city. Interfaces and common components are developed to meet the different requirements, data storage format and technology selection are chose to each business application system is constructed according to standards to ensure intercompatibility and information sharing between systems. Meanwhile, the system extends the business applications of flood risk of Luzhou city.

\section{Conclusion}

This paper develops a urban flood risk map information management system with scalability and flexible configuration. This system uses the SOA architecture, modularization design and strategy of construction in step to build a flood risk map management system platform framework; The application supporting platform based on SOA and ESB solves the problem that the information can not realize the interconnection between application systems, avoides the problem of "information island", achieves resource sharing; the system establishes a comprehensive database of flood risk maps and information collection platform, develops the flood control monitoring module and three-dimensional risk map module. The system development effectively improves the support level of flood control and provides technical basis for the development of urban flood risk map management system by taking use of the idea of human-computer interaction and applying WEBGIS real-time plotting technology, heterogeneous database integration technology and Flex technology.

\section{Acknowledgment}

This work is supported by grants from the Chinese National Natural Science Foundation under contract (No. 51209119), Natural Science Foundation of Hubei Province of China (No.2013CFC005) and Chinese National 
Natural Science Foundation (No.61370092) and Hubei Provincial Department of Education Outstanding Youth Scientific Innovation Team Support Foundation (T201410).

\section{References}

[1] Li, S. (2013). Study on urban flood risk management and practical technology - A case study of fuzhou city. China Institute of Water Resources and Hydropower Research IWHR.

[2] Cheng, X., Li, S., \& Wang, S. (2010). Urban water disaster and its coping strategy. China Water Resources, 13, 5-6.

[3] SL483-2010. (2010). Flood risk map complitation guideline.

[4] Xu, Y., et al. (2004). Food risk map system in medium and small basins in China. Scientia Geographica Sinica, 24(4), 452-457.

[5] Li, N., Cheng, X., Yuan, X., \& Hu, C. (2002). Development of Shanghai flood risk map making and flood risk information inquiry system. Water Resources Development Resource, 12(2), 48-49,.

[6] Zhang, J. (2004). Study and application of Wenzhou 3D flood risk map. Zhangjiang Hydrotechnics, 4, 11-14.

[7] Wang, Y. (2009). Design and implementation of Liaohe flood risk map information management system based on WebGIS. Dalian University of Technology.

[8] Zhang, Q. (2013). Design and implementation of flood risk map information management system based on WebGIS. Dalian University of Technology.

[9] Li, Y., Dong, C., Bo, L., \& Xuan, J. (2011). Research on urban flood risk map making technology. Water Sciences and Engineering, 5, 74-76,

[10] Li, H., \& Wan, Q. (2012). Design and implementation of flood risk map management and application system. Science of Surveying and Mapping, 37(6), 1-4.

[11] Liu, H., Liu, X., Shi, B., Wan, Z., \& Tian, K. (2014). Research on framework of integration platform for digital watershed based on SOA. Energy Education Science and Technology Part A: Energy Science and Research, 32(4), 2895-2904,

[12] Lu, J., Xu, S., \& Chen, J. (2009). Study on water resources project management information system based on GIS components. Automation in Water Resources and Hydrology, 1, 1-4.

[13] Xie, Z., et al. (2009). Actuality of irrigation water management information system development in China. Water Saving Irrigation, 2, 8-10.

[14] Liu, H., Wang, G., \& Wei, J. (2013). Research on the information system of irrigation districts based on internet of things and cloud computing. Journal of Basic Science and Engineering, 21, 17-18,

[15] Liu, H., Liu, X., Wei, J., \& Wan, Z. (2013). Research on application of comprehensive management system for rural water conservancy project. South to North Water Transfers and Water Science \& Technology, 11(6), 71-74.

[16] Zhang, Y., et al. (2011). Suggestion on water application support platform. Water Resources Informatization, $1,10-13$,

[17] Wan, D., \& Xu, J. (2009). Research on key technology of flood control decision system based on SOA. Computer Engineering and Design, 30(20), 4639-4641,

[18] Liu, C., \& Liu, D. (2013). QoS-oriented web service framework by mixed programming techniques. Journal of Computers, 8(7), 1763-1770.

[19] Li, Q., \& Zhou, M. (January 2011). The future-oriented grid-smart grid. Journal of Computers, 6(1), 98-105.

[20] Hu, M., Pan, D., \& Zhou, P. (2001). Research and Application of J2EE and AJAX Technologies in Industry Report. Journal of Computers, 6(9), 1847-1851, Sep 2011.

[21] American Psychological Association. Publication Manual of the American Psychological Association (5th ed.). Washington, D.C. 


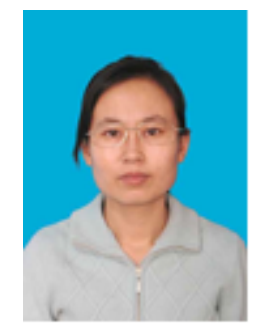

Liu Haiyan was born in Inner Mongolia Autonomous Region, P. R. China in Winter, 1978. Now she is a teacher in the Department of Computer Engineering, Beijing Information Technology College. She received the bachelor's degree in 1998 from the University of Science and Technology Beijing. Her major is computer application. Her research interests include water resources informatization, etc.

Liu Yanyan was born in Hebei Region P. R. China in Spring, 1980. Now she is a lecturer in the Department of Basic Courses, Institute of Disaster Prevention. She received the PhD degree from Dalian University of Technology in 2008. Her research interests include image processing and computer vision, etc.

Zenggang Xiong received the the MA degree from Hubei University, China, in 2005, and the PhD degree in computer science from Beijing University of Science and Technology, China, in 2009. He is now a professor in Hubei Engineering University. His research interests are in the areas of peer-to-peer computing, cloud computing, distributed systems, network security, and grid workflow. He is a member of the IEEE and the ACM.

Yu Zhen was born in Shandong Province, P. R. China in Autumn, 1983. Now she is a lecturer in School of Information, Beijing Wuzi University. Her major is computer application. Her research experiences is focused on areas of trust computation and network security. 